7 Holmberg L, Anderson H; HABITS steering and data monitoring committees. HABITS (hormonal replacement therapy after breast cancer - is it safe?), a randomised comparison: trial stopped. Lancet 2004; 363: 453-455.

8 von Schoultz E, Rutqvist LE; Stockholm Breast Cancer Study Group. Menopausal hormone therapy after breast cancer: the Stockholm randomized trial. J Natl Cancer Inst 2005; 97: 533-555.

9 Schwartz LM, Woloshin S. The media matter: a call for straightforward medical reporting. Ann Int Med 2004; 140: 226-228.

10 Bartlett C, Sterne J, Egger M. What is newsworthy? Longitudinal study of the reporting of medical research in two British newspapers. BMJ 2002; 325: 81-84.

11 National Institute for Clinical Excellence (NICE). Familial Breast Cancer: Clinical Guidelines for The Classification and Care of Women at Risk of Familial Breast Cancer in Primary, Secondary and Tertiary Care. London, UK: NICE, May 2004. http://www.nice.org.uk [Accessed 10 October 2006].

\title{
A multidisciplinary, multi-agency approach to a young person's sexual health clinic
}

\author{
Margaret Kingston
}

\section{Background to the service development}

Manchester Centre for Sexual Health (MCSH) and Brook Manchester submitted a successful joint bid for genitourinary medicine (GUM) development pilot funding in 2004 to set up a dedicated young person's clinic (YPC) at MCSH and establish a nurse practitioner post developing sexual health services at Brook with support from MCSH.

\section{How is the new service organised?}

The YPC at MCSH commenced in April 2005. An upper age limit of 19 years was set; those under 16 years are assessed by a health advisor and senior doctor using a young person's proforma and in accordance with the Fraser Guidelines (a process agreed by the Trust child protection lead). The YPC runs from $3.30 \mathrm{pm}$ to $6.30 \mathrm{pm}$ as a drop-in service accepting patients up to $5.30 \mathrm{pm}$. A full sexually transmitted infection (STI) screening service is provided and contraception offered when required. The number of patients seen at the clinic has risen steadily since it opened, with 1018 visits (790 of these new episodes) in the year April 2005-April 2006. The majority of patients are female (74\% of attendances) and the average age is 18.6 years. STIs are frequently diagnosed, with a diagnosis of chlamydial infection being made in $16 \%$ of cases and genital warts in $9 \%$.

The full complement of clinic staff comprises a

J Fam Plann Reprod Health Care 2007; 33(1): 6

Article written on behalf of the Manchester Centre for Sexual Health, Brook Manchester and Manchester Public Health Development Service, Manchester, UK

Margaret Kingston, MRCP, DFFP, Consultant in Genitourinary Medicine

Correspondence to: Dr Margaret Kingston, Manchester Royal Infirmary, Manchester Centre for Sexual Health, Oxford Road, Manchester M13 92L, UK.

E-mail: margaret.kingston@cmmc.nhs.uk consultant, a staff grade doctor, four nurse practitioners [including one from Brook and one from the Manchester Public Health Development Service (PHDS)], one health advisor, one staff nurse, two health care assistants and two clerical staff. It was decided that in order to fully utilise the skills of each member of staff appropriately we would move away from a traditional way of running a GUM clinic to a more flexible system.

\section{How does the new service work in practice?}

On arrival patients complete a simple self-triage form indicating their reason for attending the clinic with brief details of any symptoms. This form is placed at the front of their case notes. Any patient aged under 16 years is seen by the health advisor who makes the initial assessment in line with Fraser Guidelines. Using the self-triage forms the doctors and nurses take patients appropriately, with the doctors focusing on those with symptoms such as pelvic pain or genital ulceration and the nurse practitioners those requesting asymptomatic screens or attending as contacts of infection. Both doctors and nurses see those with symptoms such as vaginal or urethral discharge or warts. Treatment is dispensed by all staff members in line with clinic guidelines and nurses administer treatment according to patient group directions. Very young patients or those who have been assaulted are seen by the health advisor and consultant.

\section{What benefits does the new service offer?}

This system requires flexibility in patient allocation and cross-referral between staff occurs regularly. We have found that bottlenecks in the system occur infrequently and that patient throughput with this system is efficient. The system also required most staff to be trained in family planning and GUM. This new way of working in our department and with our Brook and PHDS colleagues has proved a success that we hope to continue to build upon in the future.

\section{READERS' CONTRIBUTIONS INVITED ON 'A BETTER WAY OF WORKING'}

Launching in this issue (see article above) is a new feature entitled 'A Better Way of Working', the purpose of which is to disseminate service delivery suggestions likely to be of interest and relevance to the Journal's readership.

Readers are invited to submit suggestions based on their own personal experience for consideration by the Journal Editor. Contributions should not exceed 250-500 words and should be written in a standardised format responding to the following four questions (or similar): Why was change needed? How did you go about implementing change? What advice would you give to others who might be considering a similar course of action? How did you show that the change had occurred?

All contributions should be submitted via the Journal's online submission system at http://jfprhc.allentrack.net. 